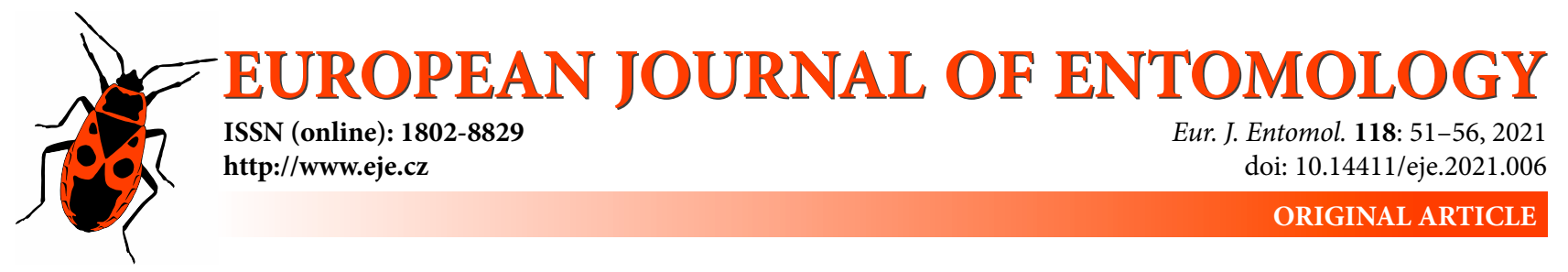

\title{
Influence of the eggs of Ephestia kuehniella (Lepidoptera: Pyralidae) reared on different diets on the performance of the predatory bug Orius laevigatus (Hemiptera: Anthocoridae)
}

\author{
Serkan PEHLivan \\ Department of Plant Protection, Faculty of Agriculture, Çukurova University, Adana, Turkey; e-mail: spehlivan@cu.edu.tr
}

Key words. Lepidoptera, Pyralidae, Ephestia kuehniella, Hemiptera, Anthocoridae, Orius laevigatus, consumption, host quality, predatory bug

\begin{abstract}
The predatory bug, Orius laevigatus (Fieber, 1860) (Hemiptera: Anthocoridae), is an important biological control agent and widely used for augmentative biological control of the western flower thrips, Frankliniella occidentalis Pergande, 1895 (Thysanoptera: Thripidae) in greenhouse crops. This bug is generally reared using the Mediterranean flour moth, Ephestia kuehniella Zeller, 1879 (Lepidoptera: Pyralidae). The aim of this study was to determine the effects of $E$. kuehniella eggs produced by adult moths reared on different larval diets on the performance of $O$. laevigatus. The diets were $95 \%$ cornmeal $+5 \%$ yeast (CY diet), $53.3 \%$ cornmeal $+26.7 \%$ wheat bran $+15 \%$ Glycerine $+5 \%$ yeast (CBGY diet) and $53.3 \%$ wheat flour $+26.7 \%$ wheat bran + $15 \%$ Glycerine $+5 \%$ yeast (WBGY diet). Laboratory studies started with newly emerged nymphs of $O$. laevigatus kept in a climate chamber at $27^{\circ} \mathrm{C}, 60 \%$ relative humidity and a $14 \mathrm{~L}: 10 \mathrm{D}$ photoperiod. Eggs of $E$. kuheniella adults that were fed on one of the three different larval diets were provided to the nymphs as a source of food and bean pods of water. Following adult emergence, all individuals were sexed, and female and male pairs were put in plastic containers $(30 \mathrm{cc})$ with eggs of $E$. kuehniella and bean pods. Nymphal development time, fecundity and longevity of $O$. laevigatus were not differently affected by feeding on the eggs of $E$. kuehniella reared on the three diets. In addition, the daily and total egg consumption of adults of $O$. laevigatus were similar. Because the $\mathrm{CY}$ diet eggs contain more nutrients, their consumption by nymphs was lower. This study indicates that the $\mathrm{CY}$ diet is an adequate diet for rearing $E$. kuehniella for producing eggs for rearing O. laevigatus.
\end{abstract}

\section{INTRODUCTION}

Most species of Anthocoridae are predators that usually feed on small insects such as aphids, thrips, psocids, psyllids, scales, small lepidopteran larvae and the eggs of insects (Pèricart, 1972; Lattin, 1999; Ballal \& Yamada, 2016). Many species of anthocorid are used as biological control agents in protected areas in European countries (EPPO, 2020). The generalist Hemipteran predator, Orius laevigatus (Fieber, 1860) (Hemiptera: Anthocoridae), has been widely used and commercially available in Europe since 1993 for controlling thrips infesting greenhouse crops, mainly Frankliniella occidentalis (Pergande) (Thysanoptera: Thripidae) (van Lenteren, 2012).

Orius laevigatus attacks a broad spectrum of arthropods but is mainly released commercially for the augmentative biological control of thrips (Chambers et al., 1993; Lattin, 1999; Keçeci \& Gürkan, 2013). Ephestia kuehniella Zeller, 1879 (Lepidoptera: Pyralidae) eggs are generally used as a food source and bean pods as an oviposition substrate for rearing predatory bugs (Castañe \& Zalom, 1994; Carvalho et al., 2011; Aragón-Sánchez et al., 2018). Lepidopteran eggs can be utilized for rearing insect predators because it is possible to mass-rear many species of Lepidoptera (Silhacek \& Miller, 1972; Tunçbilek et al., 2009; Kurtuluş et al., 2020). Moreover, eggs are easy to handle and can be prevented from hatching by freezing or UV sterilization (Isenhour \& Yeargan, 1981; Samsoe-Petersen et al., 1989). However, in order to facilitate the use of augmentative biological control there is a need to reduce production costs (Bonte \& De Clerq, 2010a).

The use of E. kuehniella eggs as the main food source in mass-rearing programs of $O$. laevigatus can increase the production cost (De Clercq et al., 2005a). This has led to a search for cheaper alternatives such as brine shrimp (Artemia sp.) cysts and many artificial diets (Arijs \& De Clercq, 2001, 2004; De Clercq et al., 2005a). However, the nutritional value of brine shrimp cysts as a source of food is not equal to that of E. kuehniella eggs (Arijs \& De Clercq, 2001). On the other hand, developing artificial diets for parasitoids and predators can simplify their mass-rearing and make it more cost-effective. However, the nutritional values of artificial diets are often inferior to the natural prey or hosts of natural enemies (Grenier, 2009). Many studies show that using alternative diets for feeding several 
generations of Orius spp. results in a reduction in the fitness of these predatory bugs, which affects their effectiveness as biological control agents (Arijs \& De Clerq, 2004; Ferkovich et al., 2007; Venkatesan et al., 2008; Bonte \& De Clerq, 2008, 2010a). Inspite of this, lepidopteran eggs have been used as the standard food in the commercial massrearing of Orius spp. since the early 1990s (Alauzet et al., 1994; van Lenteren \& Tommasini, 2003). Moreover, there is no evidence that the performance of predatory bugs used in biological control programs has been affected by their rearing diet (Bonte \& De Clerq, 2010b).

Bonte \& De Clercq $(2008,2010 \mathrm{a})$ report that the reproductive fitness of $O$. laevigatus is greater when reared on $E$. kuehniella eggs than on other artificial diets. Many studies have shown that E. kuehniella is a nutritionally superior food for natural enemies (Cocuzza et al., 1997; Specty et al., 2003; De Clercq et al., 2005b; Song et al., 2019; Ricupero et al., 2020). However, there are virtually no studies on the effects of different artificial diets on the nutritional quality of E. kuehniella eggs as a food source for species of Orius. Therefore, determining the effects of E. kuehniella eggs, which are obtained by rearing this moth on different larval diets, on the fitness of $O$. laevigatus is important for optimizing the mass rearing of this predator specifically for biological control purposes. Therefore, the nutritional quality of E. kuehniella eggs in terms of the biological parameters and consumption by $O$. laevigatus were determined in this study.

\section{MATERIALS AND METHODS}

\section{Insect rearing}

\section{Ephestia kuehniella}

The initial colony of the Mediterranean flour moth, E. kuehniella was obtained from the Biyolojik Tarım Company, Erzin, Hatay, Turkey. The moths were maintained for six months in the Laboratory of Entomology (hereafter referred as the laboratory), Department of Plant Protection, Çukurova University, Adana, Turkey before they were used in the experiments. Three different diets consisting, respectively, of $95 \%$ cornmeal $+5 \%$ yeast (CY diet), $53.3 \%$ cornmeal $+26.7 \%$ wheat bran $+15 \%$ Glycerine $+5 \%$ yeast (CBGY diet) or $53.3 \%$ wheat flour $+26.7 \%$ wheat bran $+15 \%$ Glycerine $+5 \%$ yeast (WBGY diet) were used to rear the larvae of E. kuehniella in a climate chamber at $25 \pm 1^{\circ} \mathrm{C}$, $60 \pm 10 \%$ relative humidity and a $14 \mathrm{~L}: 10 \mathrm{D}$ photoperiod. One $\mathrm{kg}$ amounts of the three diets were prepared and each placed in a plastic container $(34 \times 23 \times 7 \mathrm{~cm})$ to which 10 eggs were added per $1 \mathrm{~g}$ of food. The CY diet (I) consisted of $950 \mathrm{~g}$ cornmeal and 50 g yeast; the CBGY diet (II): $533 \mathrm{~g}$ cornmeal, $267 \mathrm{~g}$ wheat bran, $150 \mathrm{ml}$ glycerine and $50 \mathrm{~g}$ yeast and WBGY diet (III): 533 $\mathrm{g}$ wheat flour, $267 \mathrm{~g}$ wheat bran, $150 \mathrm{ml}$ glycerine and $50 \mathrm{~g}$ yeast. In each case the dry components were mixed first and then glycerine was added to the mixture. Corrugated cardboard plates were placed inside the containers to provide a pupation site and then containers were covered with fine muslin cloth. Each moth colony was reared on one of the diets for one generation before the trials. Following adult emergence, the containers were checked three times a week when any adults of E. kuehniella were collected with the help of an electric suction aspirator and transferred to egg laying containers ( 1 liter in volume). Eggs were collected from these containers every two days. Some of these eggs were used for maintaining the E. kuehniella colony, while others were frozen and kept for rearing O. laevigatus. All diets used in the experiments in the current study were used in a previous study by Kurtuluş et al. (2020) on the most promising ways of rearing $E$. kuehniella in the laboratory.

\section{Orius laevigatus}

O. laevigatus were collected from pepper plants growing in open fields in Adana, Turkey in 2018 and maintained in the laboratory. The predatory bug was identified by using the identification key of Péricart (1972) and then reared separately in plastic jars (1 liter in volume) with a perforated lid ( $5 \mathrm{~cm}$ diameter). The jars were sealed with mesh cloth for ventilation and to prevent escape. Adults and nymphs of this predatory bug were fed (ad libitum) with U.V sterilized E. kuehniella eggs and provided with bean pods as an oviposition substrate and source of water. Adults and nymphs of this predatory bug were kept in separate cages to reduce cannibalism. Moreover, to avoid genetic degeneration, new individuals were collected in the field and added to the laboratory colony at least twice a year.

\section{Effects of the different artificial diests fed to Ephestia kuehniella on biological parameters of Orius laevigatus}

These experiments started with 90 newly emerged nymphs of O. laevigatus kept in a climate chamber at $27 \pm 1{ }^{\circ} \mathrm{C}, 60 \pm 10 \%$ relative humidity and a 14L: 10D photoperiod. Eggs of E. kuehniella fed on one of the three different diets were provided as a source of food and bean pods as a source of water for the nymphs. Three times a week, the nymphs were fed $75 \mathrm{~min}$ U.V-sterilized (UVB light 280-315 nm) E. kuehniella eggs glued to pieces of cardboard with Arabic gum. The nymphs were checked twice a day and nymphal development times were determined. Following adult emergence, all individuals were sexed, and one female and one male were put in a plastic container $(30 \mathrm{cc})$ along with eggs of E. kuehniella and bean pods and the pre-oviposition, oviposition, post-oviposition, longevity and fecundity of females recorded under the same experimental conditions as above. The containers were checked daily until the end of the pre-oviposition period and then every two days to determine the other biological parameters of $O$. laevigatus. The experiments were terminated when all individuals were dead.

\section{Consumption by Orius laevigatus of the eggs of Ephestia kuehniella reared on different artificial diets}

This experiment started in each case with 45 newly emerged nymphs of $O$. laevigatus that were fed eggs of E. kuehniella produced in one of the three diets and provided with fresh bean pods as a source of water. The number of eggs of E. kuehniella consumed by the nymphs of $O$. laevigatus were determined every two days. Following adult emergence, all individuals were sexed and one female and one male were put in a plastic container (30 cc) for mating. After four hours, the males were transferred to other containers. The consumption of E. kuehniella eggs by $O$. laevigatus adults (females and males) was recorded over a period of 15 days. Two hundred fresh eggs were placed in each container every two days for both nymphs and adults.

\section{Statistical analysis}

The experiments were carried out in a completely randomized design. Kolmogorov-Smirnov test and Levene's test were used to determine normality and homogeneity of variance, respectively. One-way Analysis of Variance (ANOVA) of nymphal development time, pre-oviposition, oviposition, post-oviposition, longevity and fecundity of adults of $O$. laevigatus was carried out using Tukey's HSD post hoc mean separation. The nymphal development experiments were carried out in a completely randomized design with at least 30 replicates for each diet. Data on consump- 
tion (nymphs and adults) were also analyzed using one-way ANOVA followed by Tukey's post hoc test. The consumption experiments were carried out in a completely randomized design with at least 15 replicates for each diet. All analyses were done using SPSS $^{\circ}$ (ver. 25).

\section{RESULTS}

\section{Effects of the different artificial diets on the nymphal development of Orius laevigatus}

In this study, the development time of second nymphal stage was shorter when the eggs produced by moths reared on the CBGY diet were provided as food. But the development time of the other nymphal stages and total development time of $O$. laevigatus were not significantly affected differently by the eggs of E. kuehniella reared on the different larval diets $\left(\mathrm{F}_{2,85}=1.453, \mathrm{p}=0.240\right.$; Table 1$)$.

\section{Effects of different artificial diets on the biological parameters of adults of Orius laevigatus}

The biological parameters of adults of $O$. laevigatus recorded are shown in Table 2. The different artificial diets did not significantly affect the pre-oviposition $\left(\mathrm{F}_{2,35}=\right.$ $2.005, \mathrm{p}=0.150)$, oviposition $\left(\mathrm{F}_{2,35}=0.141, \mathrm{p}=0.869\right)$ and post-oviposition $\left(\mathrm{F}_{2,35}=0.086, \mathrm{p}=0.918\right)$ periods. Moreover, the longevity of adults of $O$. laevigatus and their fecundity did not differ statistically when reared and fed on eggs produced by moths reared on the different artificial diets $\left(\mathrm{F}_{2,35}=0.168, \mathrm{p}=0.846, \mathrm{~F}_{2,35}=0.205, \mathrm{p}=0.816\right.$; Fig. 1 , respectively).

\section{Effects of different artificial diets fed to the moths on the consumption of their eggs by Orius laevigatus}

The consumption of eggs by the different stages of $O$. laevigatus are recorded in Table 3. The consumption of eggs by nymphs of $O$. laevigatus differed significantly on the eggs of the moths reared on the different artificial diets

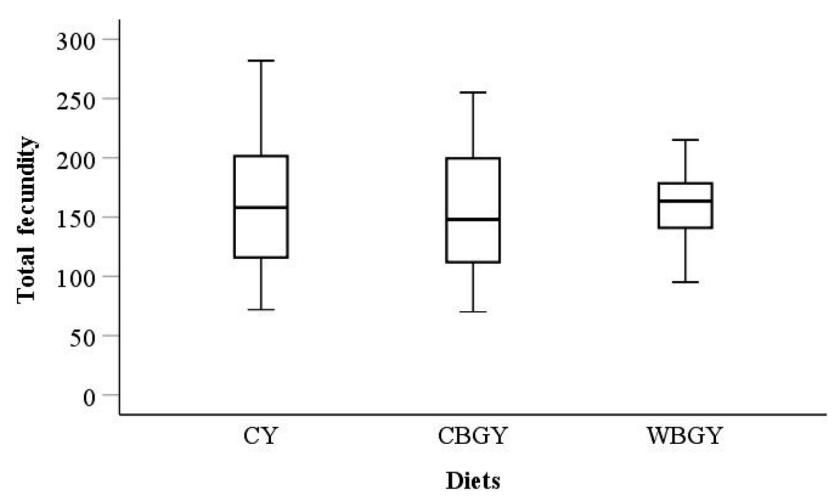

Fig. 1. The lifetime fecundity of Orius laevigatus fed on the eggs of E. kuehniella reared on the different diets.

$\left(\mathrm{F}_{2,42}=5.845, \mathrm{p}=0.006\right)$. The nymphs consumed fewer of the eggs produced by moths reared on the CY diet. However, the different artificial diets used for rearing the moths did not significantly affect the daily and total consumption of the eggs of these moths by adults of $O$. laevigatus in the first fifteen days of their adult life $\left(\mathrm{F}_{2,42}=0.155, \mathrm{p}=0.857\right)$.

\section{DISCUSSION}

The success in rearing anthocorids depends on several factors, with the type of food being one of the most crucial (Calixto et al., 2013). E. kuehniella eggs are considered to be a nutritionally high quality food for natural enemies (Cocuzza et al., 1997; Specty et al., 2003; De Clercq et al., 2005b; Song et al., 2019; Ricupero et al., 2020). The nymphal development time of $O$. laevigatus fed eggs of $E$. kuehniella recorded in the literature is for different temperatures and different sources of water. Moreover, a number of previous studies used commercially available eggs of $E$. kuehniella. At $23^{\circ} \mathrm{C}$, the development time is 13.0 and 11.7 days on sharp pepper seedlings (Bonte \& De Clercq, 2008,

Table 1. The nymphal development times (days) of $O$. laevigatus fed on eggs of $E$. kuehniella reared on the different diets.

\begin{tabular}{|c|c|c|c|c|c|c|c|}
\hline Diet & $\mathrm{n}$ & First instar nymph & 2nd & $3 r d$ & 4th & 5 th & Total \\
\hline$C Y^{* *}$ & 30 & $2.63 \pm 0.09 a^{*}$ & $1.83 \pm 0.08 a$ & $1.83 \pm 0.12 a$ & $2.23 \pm 0.09 a$ & $1.37 \pm 0.13 a$ & $9.90 \pm 0.19 a$ \\
\hline CBGY & 29 & $2.83 \pm 0.09 a$ & $1.31 \pm 0.08 b$ & $1.90 \pm 0.09 a$ & $2.24 \pm 0.11 \mathrm{a}$ & $1.17 \pm 0.07 a$ & $9.45 \pm 0.18 a$ \\
\hline WBGY & 29 & $2.55 \pm 0.09 a$ & $1.86 \pm 0.11 a$ & $1.79 \pm 0.14 a$ & $2.24 \pm 0.11 \mathrm{a}$ & $1.24 \pm 0.08 a$ & $9.69 \pm 0.19 a$ \\
\hline
\end{tabular}

* Means with same letter in the same column are not statistically significant according to Tukey's HSD test $(P<0.05)$; ${ }^{* *}$ Diet names were constructed using the initials of the ingredients in each diet. C - cornmeal; W - wheat flour; B - wheat bran; $\mathrm{G}-\mathrm{glycerine;} \mathrm{Y} \mathrm{-} \mathrm{yeast.}$

Table 2. The biological traits recorded in days of $O$. laevigatus fed on eggs of $E$. kuehniella reared on the different diets.

\begin{tabular}{|c|c|c|c|c|c|}
\hline Diet & $\mathrm{n}$ & Pre-oviposition period (days) & Oviposition period (days) & Post-oviposition period (days) & Longevity (days) \\
\hline$\overline{\mathrm{CY}}$ & 10 & $3.80 \pm 0.36 a^{*}$ & $18.90 \pm 2.34 a$ & $2.70 \pm 0.26 a$ & $25.40 \pm 2.30 a$ \\
\hline CBGY & 12 & $2.92 \pm 0.34 a$ & $19.08 \pm 2.58 a$ & $2.83 \pm 0.34 a$ & $24.83 \pm 2.50 a$ \\
\hline WBGY & 16 & $3.25 \pm 0.21 \mathrm{a}$ & $20.31 \pm 1.62 a$ & $2.88 \pm 0.27 a$ & $26.44 \pm 1.63 a$ \\
\hline
\end{tabular}

* Means with the same letter in the same column are not statistically significant according to Tukey's HSD test at (P < 0.05$)$.

Table 3. The consumption of nymphs and adults of Orius laevigatus of the eggs of E. kuehniella reared on the different diets.

\begin{tabular}{lcccc}
\hline Diet & $\mathrm{n}$ & Total nymphal consumption & Daily adult consumption & Total adult consumption \\
\hline CY & 15 & $137.20 \pm 6.16 b^{*}$ & $25.29 \pm 2.17 a$ & $379.33 \pm 32.55 a$ \\
CBGY & 15 & $148.27 \pm 7.24 \mathrm{ab}$ & $23.64 \pm 2.38 \mathrm{a}$ & $354.53 \pm 35.73 \mathrm{a}$ \\
WBGY & 15 & $169.00 \pm 6.57 \mathrm{a}$ & $24.40 \pm 1.68 \mathrm{a}$ & $365.93 \pm 25.33 \mathrm{a}$
\end{tabular}

* Means with the same letter in the same column are not statistically significant according to Tukey's HSD test (P < 0.05$)$. 
2010a) and 13.5 days on bean pods (Bonte \& De Clercq, 2011). At $25^{\circ} \mathrm{C}$ and $26^{\circ} \mathrm{C}$, total nymphal development is 13.2 days on geranium leaves (Pelargonium peltatum L.) (Alauzet et al.,1994) and 11.8 days on bean pods (Tommasini et al., 2004), respectively. In this study, total nymphal development time was shorter than that recorded in previous studies. This could be due to the different oviposition substrates used and that the temperature was higher in this study. Moreover, in the current study, the artificial diets did not significantly affect the pre-oviposition periods. Cocuzza et al. (1997) and Bonte \& De Clercq (2008) report that the pre-oviposition period of $O$. laevigatus at $23^{\circ} \mathrm{C}$ is 3.2 days on the Spanish pepper plant (Capsicum annuum L. cv. 'Creta', long red) and 4.7 days, on sharp pepper seedlings, respectively. Tommasini et al. (2004) report that the pre-oviposition period of four different species of Orius [Orius insidiosus (Say, 1832), O. laevigatus, Orius majusculus (Reuter, 1879) and Orius niger (Wolff, 1881) (Hemiptera: Anthocoridae)] range between 3.2 to 6.7 days on bean pods at $26^{\circ} \mathrm{C}$. In the current study, the pre-oviposition period is similar to that reported in previous studies even though bean pods were provided as a source of water and an oviposition substrate.

Longevity is another factor that can directly affect the fecundity of insects (Leather, 1988). Cocuzza et al. (1997) and Bonte \& De Clerq (2008) report that the longevity of females of $O$. laevigatus is 41.9 and 50.2 days, respectively. However, Alauzet et al. (1994), Tavella et al. (1994) and Tommasini et al. (2004) report shorter longevities (34.5, 23.0 and 38.6 days, respectively) when reared under similar conditions. In the current study, longevity ranged between 24.83 to 26.44 days, which is lower than the average of the values reported in the previous studies. This could be due to the higher temperature used in this study. Zhang et al. (2012) and Ali et al. (2020) report that longevity decreases with increase in temperature when adults of Orius similis Zheng (Hemiptera: Anthocoridae) and Orius strigicollis (Poppius) (Hemiptera: Anthocoridae) are fed on Tetranychus cinnabarinus (Boisd.) (Acari: Tetranychidae) and Pectinophora gossypiella Saunders (Lepidoptera: Gelechiidae) eggs, respectively.

Because of their high nitrogen content, lepidopteran eggs are of higher nutritional quality than other food sources, including the predators' natural prey (Ferkovich et al., 2007). The developmental and reproductive fitness of $O$. laevigatus is greater when reared on eggs of E. kuehniella (Cocuzza et al., 1997; Tommasini et al., 2004; Bonte \& De Clerq, 2008). Fauvel et al. (1987) and Cocuzza et al. (1997), respectively, report that Macrolophus caliginosus Wagner (Heteroptera: Miridae) and O. laevigatus perform better when reared on eggs of E. kuehniella than on some of their natural prey. Aragón-Sánchez et al. (2018) report that the increase in a population of $O$. laevigatus fed on Spodoptera exigua (Hübner) (Lepidoptera: Noctuidae) eggs is similar to that when naturally feeding on $E$. kuehniella and F. occidentalis. Furthermore their findings highlight the promising role of the eggs of $S$. exigua as an alternative food for use in laboratory tests. However, the cost of mass-rearing $S$. exigua is considerably greater than that of E. kuehniella. Moreover, Ferkovich \& Shapiro (2005) note the presence of a specific nutritional factor, in certain lepidopteran eggs, enhances the fecundity of predators. Lifetime fecundity is often considered to be a crucial factor determining the fitness of insects reared on artificial diets (Grenier \& De Clercq, 2003). In the present study, the fecundity of $O$. laevigatus did not differ on the eggs of the moths reared on the three different artificial diets (Fig. 1). Tavella et al. (1994) and Tommasini et al. (2004) report that the fecundity of $O$. laevigatus is 104.6 and $118.6 \mathrm{eggs} /$ female, respectively when reared on eggs of E. kuehniella eggs. Other researchers report higher fecundities ranging from 141 eggs to 198.0 eggs/female (Alauzet et al., 1994; Cocuzza et al., 1997; Vacante et al., 1997; Bonte \& De Clerq, 2008). In the current study, the average fecundity of $O$. laevigatus was 150 eggs/female. These differences may be due to the different temperatures and oviposition substrates used in the experiments.

The nymphs of this predator consumed fewer of the eggs produced by the moths reared on the CY diet (Table 3). Van den Meiracker (1999) report that female and male nymphs of $O$. insidiosus consume a total of 54.73 and 48.28 eggs, respectively. Moreover, total nymphal consumption of $O$. niger is 77.10 and 67.25 eggs for females and males. Tommasini et al. (2004) also report different total consumptions of eggs of E. kuehniella for different species of Orius (O. insidiosus 94.3 eggs, O. majusculus 99.4 eggs, $O$. laevigatus 174.6 eggs and $O$. niger 183.5 eggs). In the current study, total nymphal consumption of $O$. laevigatus of eggs produced by moths reared on the WBGY diet is similar to that reported by Tommasini et al. (2004). This may be related to the nutritional value of the E. kuehniella eggs. Moreover, it is not possible to compare this value because the ingredients of the E. kuehniella diets used in the other studies is unknown. However, the artificial diets did not affect the daily and total consumption by adults of $O$. laevigatus in the first 15 days of their life (Table 3 ). Van den Meiracker (1999) and Calixto et al. (2013) report that the daily consumption of E. kuehniella eggs by $O$. insidiosus is 8 eggs/female and 15.7 eggs/female, respectively. In addition, Tommasini et al. (2004) report that the daily consumption of eggs by four species of Orius ( $O$. insidiosus, O. laevigatus, O. majusculus and $O$. niger) is 25 eggs. Bonte \& De Clerq (2010b) report that the consumption of eggs of E. kuehniella by O. laevigatus is 21.5 eggs/day. The findings of the current study are similar to those reported by Tommasini et al. (2004) and Bonte \& De Clerq (2010b). The consumption of the nymphal and adults stages can differ. Bonte \& De Clerq (2008) report that adult diet of $O$. laevigatus had a greater effect than the nymphal diet on its fecundity, which is directly related to their consumption. Moreover, adults of $O$. laevigatus fed on eggs of E. kuehniella were clearly able to compensate for any deficiencies in their nymphal diet.

Understanding the role of artificial diets in the development, fecundity and egg consumption of predatory bugs could improve the success of biological control programs 
by ensuring a greater efficiency of the predators used in augmentative releases. The use of the eggs of E. kuehniella as the main source of food in the mass rearing of $O$. laevigatus can increase production costs (De Clercq et al., 2005a). Based on the current study, the three artificial diets fed to the moth did not affect either the development or fecundity of $O$. laevigatus. In addition, the CY diet resulted in nymphs consuming fewer eggs but had no effect on the egg consumption of adults. Moreover, the CY diet has the advantage that it is cheaper, more easily produced and less likely to be contaminated due to the lack of liquid in the diet. For this reason, the CY diet could be a suitable standard diet for the rearing of $O$. laevigatus. Further research on the effects of the CY diet on some biological parameters of this bug in subsequent generations should be conducted. In addition, the efficacy of parasitoids and predators that are reared on the CY diet should be determined in the field.

ACKNOWLEDGEMENTS. The author thanks E. Atakan, T.D. Achiri and M. Ahmed for their kind collaboration and helpful comments on the manuscript.

\section{REFERENCES}

Alauzet C., Dargagnon D. \& Malausa J.C. 1994: Bionomics of a polyphagous predator: Orius laevigatus (Het.: Anthocoridae). —Entomophaga 39: 33-40.

Ali S., Zhu Q., Jaleel W., Rehman S.U., Rasheed M.A., Khan M.M., Islam Y., Hafeez M. \& Zhou X. 2020: Determination of fitness traits of Orius strigicollis Poppius (Hemiptera: Anthocoridae) on Pectinophora gossypiella (Lepidoptera: Gelechiidae) using two-sex life table analysis. — PeerJ 8: e9594, $26 \mathrm{pp}$.

Aragón-SÁnchez M., RomÁn-Fernández L.R., MartíneZ-García H., Aragón-García A., Pérez-Moreno I. \& Marco-Mancebón V.S. 2018: Rate of consumption, biological parameters, and population growth capacity of Orius laevigatus fed on Spodoptera exigua. - BioControl 63: 785-794.

Ariss Y. \& De Clerce P. 2001: Rearing Orius laevigatus on cysts of the brine shrimp Artemia franciscana. - Biol. Contr. 21: 79-83.

Ariss Y. \& De Clerce P. 2004: Liver-based artificial diets for the production of Orius laevigatus. - BioControl 49: 505-516.

Ballal C.R. \& Yamada K. 2016: Anthocorid predators. In Omkar (ed.): Ecofriendly Pest Management for Food Security. Elsevier, New York, pp. 183-216.

Bonte M. \& De ClercQ P. 2008: Developmental and reproductive fitness of Orius laevigatus (Hemiptera: Anthocoridae) reared on factitious and artificial diets. - J. Econ. Entomol. 101: $1127-1133$.

Bonte M. \& De ClercQ P. 2010a: Impact of artificial rearing systems on the developmental and reproductive fitness of the predatory bug, Orius laevigatus. - J. Insect Sci. 10: 104, 11 pp.

Bonte M. \& De ClercQ P. 2010b: Influence of diet on the predation rate of Orius laevigatus on Frankliniella occidentalis. BioControl 55: 625-629.

Bonte M. \& De ClercQ P. 2011: Influence of predator density, diet and living substrate on developmental fitness of Orius laevigatus. - J. Appl. Entomol. 135: 343-350.

Calixto A., Bueno M., Montes V.H.P., Silva F.C. \& Van Lenteren J.C. 2013: Effect of different diets on reproduction, longevity and predation capacity of Orius insidiosus (Say) (Hemiptera: Anthocoridae). - Biocontr. Sci. Technol. 23: 1245-1255.
Carvalho L.M., Bueno V.H.P. \& CAstañe C. 2011: Olfactory response towards its prey Frankliniella occidentalis of wild and laboratory reared Orius insidiosus and Orius laevigatus. $-J$. Appl. Entomol. 135: 177-183.

Castañe C. \& Zalom F.G. 1994: Artificial oviposition substrate for rearing Orius insidiosus (Hemiptera, Anthocoridae). Biol. Contr. 4: 88-91.

Chambers R.J., Long S. \& Helyer N.L. 1993: Effectiveness of Orius laevigatus (Hemiptera: Anthocoridae) for the control of Frankliniella occidentalis on cucumber and pepper in the UK. - Biocontr. Sci. Technol. 3: 295-307.

Cocuzza G.E., De Clerce P., Van de Veire M., De Cock A., DeGHEELE D. \& VACANTE V. 1997: Reproduction of Orius laevigatus and Orius albidipennis on pollen and Ephestia kuehniella eggs. - Entomol. Exp. Appl. 82: 101-104.

De Clercq P., Merlevede F. \& Tirry L. 1998: Unnatural prey and artificial diets for rearing Podisus maculiventris (Heteroptera: Pentatomidae). - Biol. Contr. 12: 137-142.

De Clercq P., Ariss Y., Van Meir T., Van Stappen G., Sorgeloos P., Dewettinck K., Rey M., Grenier S. \& Febvay G. 2005a: Nutritional value of brine shrimp cysts as a factitious food for Orius laevigatus (Heteroptera: Anthocoridae). — Biocontr. Sci. Technol. 15: 467-479.

De Clercq P., Bonte M., van Speybroeck K., Bolckmans K. \& Deforce K. 2005b: Development and reproduction of Adalia bipunctata (Coleoptera: Coccinellidae) on eggs of Ephestia kuehniella (Lepidoptera: Phycitidae) and pollen. - Pest Manag. Sci. 61: 1129-1132.

EPPO (European and Mediterranean Plant Protection OrganiZATION) 2020: Liste d'agents de lutte biologique largement utilisés dans la région OEPP. PM 6/3 Français Ver. 2020. URL: https://www.eppo.int/media/uploaded_images/RESOURCES/ eppo_standards/pm6/pm6-03-2020-fr.pdf (last accessed February 2021).

Fauvel G., Malausa J.C. \& Kaspar B. 1987: Etude en laboratoire des principales caractéristiques biologiques de Macrolophus caliginosus (Heteroptera: Miridae). - Entomophaga 32: 529-543.

FERKovich S.M. \& Shapiro J.P. 2005: Enhanced oviposition in the insidious flower bug, Orius insidiosus (Hemiptera: Anthocoridae), with a partially purified nutritional factor from prey eggs. - Fla Entomol. 88: 253-257.

Ferkovich S.M., Venkatesan T., Shapiro J.P. \& Carpenter J.E. 2007: Presentation of artificial diet: effects of composition and size of prey and diet domes on egg production by Orius insidiosus (Heteroptera: Anthocoridae). — Fla Entomol. 90: 502-508.

GRENIER S. 2009: In vitro rearing of entomophagous insects - past and future trends: a minireview. - Bull. Insectol. 62: 1-6.

Grenier S. \& De Clerce P. 2003: Comparison of artificially vs. naturally reared natural enemies and their potential for use in biological control. In van Lenteren J.C. (ed.): Quality Control and Production of Biological Control Agents. CAB International, Wallingford, pp. 115-131.

ISENHOUR D.J. \& YEARGAN K.V. 1981: Effect of temperature on the development of Orius insidiosus, with notes on laboratory rearing. - Ann. Entomol. Soc. Am. 74: 114-116.

KeCECI M. \& GÜRKAN M.O. 2013: Biological control of Western flower thrips, Frankliniella occidentalis with Orius species in eggplant greenhouses in Turkey. - Turk. J. Entomol. 37: 467-476.

Kurtulus A., Pehlivan S., Achiri T.D. \& Atakan E. 2020: Influence of different diets on some biological parameters of the Mediterranean flour moth, Ephestia kuehniella Zeller (Lepidoptera: Pyralidae). - J. Stor. Prod. Res. 85: 101554, 6 pp. 
LatTin J.D. 1999: Bionomics of the Anthocoridae. - Annu. Rev. Entomol. 44: 207-231.

LEATHER S.R. 1988: Size, reproductive potential and fecundity in insects: things aren't as simple as they seem. - Oikos 51: 386-389.

PérICART J. 1972: Hémiptères: Anthocoridae, Cimicidae et Microphysidae de l'Ouest Paléartique. Masson et Cie, Paris, 402 pp.

Ricupero M., Dai C., Siscaro G., Russo A., Biondi A. \& Zappalà L. 2020: Potential diet regimens for laboratory rearing of the harlequin ladybird. - BioControl 65: 583-592.

Samsoe-Petersen L., Bigler F., Bogenschütz H., Brun J., Hassan S.A., Helyer N.L., Kühner C., Mansour F., Naton E., Oomen P.A. \& ET AL. 1989: Laboratory rearing techniques for 16 beneficial arthropod species and their prey/hosts. - Z. Pflkrankh. Pflschutz. / J. Plant Dis. Prot. 96: 289-316.

Silhacek D.L. \& Miller G.L. 1972: Growth and development of the Indian meal moth, Plodia interpunctella (Lepidoptera: Phycitidae), under laboratory mass-rearing conditions. - Ann. Entomol. Soc. Am. 65: 1084-1087.

Song Z.W., Nguyen D.T., Li D.S. \& De Clerce P. 2019: Continuous rearing of the predatory mite Neoseiulus californicus on an artificial diet. - BioControl 64: 125-137.

Specty O., Febvay G., Grenier S., Delobel B., Piotte C., Pageaux J.F., Ferran A. \& Guillaud J. 2003: Nutritional plasticity of the predatory ladybeetle Harmonia axyridis (Coleoptera: Coccinellidae) comparison between natural and substitution prey. - Arch. Insect Biochem. Physiol. 52: 81-91.

Tavella L., Alma A. \& Arzone A. 1994: Attività predatrice di Orius spp. (Anthocoridae) su Frankliniella occidentalis (Perg.)(Thripidae) in coltura protetta di peperone. - Informat. Fitopatol. 44: 40-43.

Tommasini M.G., van Lenteren J.C. \& Burgio G. 2004: Biological traits and predation capacity of four Orius species on two prey species. - Bull. Insectol. 57: 79-94.
TunçBilek A.S., Canpolat U. \& Sumer F. 2009: Suitability of irradiated and cold-stored eggs of Ephestia kuehniella (Pyralidae: Lepidoptera) and Sitotroga cerealella (Gelechidae: Lepidoptera) for stockpiling the egg-parasitoid Trichogramma evanescens (Trichogrammatidae: Hymenoptera) in diapause. - Biocontr. Sci. Technol. 19: 127-138.

Vacante V., Cocuzza G.E., De Clerce P., Van De Veire M. \& TIRRY L. 1997: Development and survival of Orius albidipennis and Orius laevigatus (Het.: Anthocoridae) on various diets. —Entomophaga 42: 493-498.

Vandekerkhove B., Parmentier L., Van Stappen G., Grenier S., Febvay G., Rey M. \& De Clerce P. 2009: Artemia cysts as an alternative food for the predatory bug Macrolophus pygmaeus. - J. Appl. Entomol. 133: 133-142.

VAN DEN MEIRACKER R.A.F. 1999: Biocontrol of Western Flower Thrips by Heteropteran Bugs. PhD Thesis, University of Amsterdam, $141 \mathrm{p}$.

VAN LENTEREN J.C. 2012: The state of commercial augmentative biological control: plenty of natural enemies, but a frustrating lack of uptake. - BioControl 57: 71-84.

VAn Lenteren J.C. \& Tommasini M.G. 2003: Mass production, storage, shipment and release of natural enemies. In Van Lenteren J.C. (ed.): Quality Control and Production of Biological Control Agents: Theory and Testing Procedures. CAB International, Wallingford, pp. 181-189.

Venkatesan T., Jalali S.K., Samurthy K.S. \& Bhaskaran T.V. 2008: Development, survival and reproduction of an anthocorid predator (Orius tantillus) on artificial and natural diets. Indian J. Agr. Sci. 78: 102-105.

Zhang S.C., Zhu F., Zheng X.L., Lei C.L. \& Zhou X.M. 2012: Survival and developmental characteristics of the predatory bug Orius similis (Hemiptera: Anthocoridae) fed on Tetranychus cinnabarinus (Acari: Tetranychidae) at three constant temperatures. - Eur. J. Entomol. 109: 503-508.

Received October 27, 2020; revised and accepted January 21, 2021 Published online February 8, 2021 